\title{
Evolution of Computer Science Education in the Purview of Free Education
}

\author{
S.T. Nandasara \\ University of Colombo School of Computing (UCSC), Colombo, Sri Lanka \\ stn@ucsc.1k, nandasara@yahoo.com
}

\begin{abstract}
Sri Lanka was one of the first developing nations to understand the importance of investing in human resources and promoting gender equality. Advances made by the country in health and education are at par with those of the advanced countries. Near universal literacy and a well-developed system of school education, places Sri Lanka as a leader in education in South Asia and amongst the top-performing countries in the entire world. High priority was given to education for over six decades whereby free education has resulted in an increase of school enrolment from 1 million in 1947 to a peak of 4.2 million in the mid-nineties, achieving universal primary education and a high level of participation in secondary education. Net enrolment ratio (in 2004) of $97.9 \%$ at primary level, a completion ratio of $95 \%$, and a gender parity of $96 \%$ are laudable achievements.

In terms of multi-disciplinary e-readiness criteria, Sri Lanka is also ranked higher than the neighbouring Asian countries in spite of the relatively slow penetration of computers, internet and other telecommunication media. According to the United Nations Report on e-Government Survey of 2008, Sri Lanka is ranked at eighth among twenty other countries in the Southeast/South Asian region.
\end{abstract}

Keywords: Computer science education, university, Sri Lanka, free education, historical perspective.

\section{The Land of Free Education}

The Democratic Socialist Republic of Sri Lanka, known in short as Sri Lanka is a free, sovereign, and independent democratic socialist republic. It is an island in the Indian Ocean located close and to the north of the equator. Sri Lanka has a total land area of 65,610 sq. km, encompassing beaches, green vegetation, and a mountainous mass somewhat south of centre with heights reaching about 2,500 meters, surrounded by broad plains.

In 1805, after the British invasion, the education system in Sri Lanka was developed based on the British System. Sri Lanka received independence from the British on the $4^{\text {th }}$ February 1948 . Hon. C. W. W. Kannangara, the then Minister of Education in the State Council (1931-1947) introduced several far reaching policies in education, a few years before receiving independence from the British. They included 
primary education in the mother tongue, free education for primary, secondary and higher education, establishment of a number of quality schools in all regions of the country and the provision of a free mid-day meal in schools. The striding measures earned him the name 'The Father of Free Education' and have contributed immensely towards opening up higher education to the masses as opposed to the elite that benefited till then.

In Sri Lanka, though the government plays the primary role in education, it does not claim monopoly over it. There are many Buddhist pansala and pirivena, Muslim schools, and Christian schools in the country. Roman Catholic Churches alone operates several hundred schools enrolling over 80,000 children.

\section{Origin, Size and Growth of Higher Education}

The roots of the higher education system in Sri Lanka can be traced back to the Ceylon Medical College established in 1870 by the then Government under the leadership of the Governor, Sir Hercules Robinson and setting up of the Ceylon University College in 1921. This College affiliated to the University of London to prepared students for external examinations conducted by it. When the University of Ceylon (later renamed as University of Sri Lanka) was established in $1^{\text {st }}$ July 1942, by proclamation under the Ceylon University Ordinance, No. 20 of 1942, both these Colleges were amalgamated with it. The Ceylon Medical Collage became the Faculty of Medicine, and the Ceylon University Collage was divided into Faculties of Oriental Studies, and Arts and Science. The Faculty of Engineering was established in Colombo in 1956. Since the establishment of Ceylon Medical College in 1870, it could claim to have been associated with higher education for over 140 years.

The University of Ceylon was established in Colombo, in 1942, and on the $6^{\text {th }}$ October 1952 a new campus in Peradeniya, Kandy was inaugurated in the tea and rubber plantation near the banks of Mahaweli River, the longest river in the country. Sir Ivor Jennings was the first Vice-Chancellor to the Peradeniya Campus. Dentistry, which was confined initially to one department in the Faculty of Medicine in Colombo, was moved to Peradeniya in 1954, and the department was renamed as the Dental School, with one unitary department of Dental Surgery. The Faculty of Engineering which was initially established in Colombo in 1956 was transferred to Peradeniya in 1965. In 1967, it was made a separate university with the name 'University of Ceylon Peradeniya' and it became the independent 'University of Peradeniya' in 1979. Today, the Peradeniya University stands as a prominent educational institution in the country, catering to the needs of students from a variety of academic streams and ethnic groups that have been at Peradeniya for over the last 60 years.

Likewise, for technical education, the Government Technical School (GTS), established in 1893 at Maradana, Colombo (its name was changed to the Ceylon Technical College-CTC in 1906) was the first institution for formal technical education in Sri Lanka. The CTC provided technical education in Civil, Electrical and Mechanical Engineering fields and prepared candidates for the external degrees in Engineering of the University of London in England. In 1960, the technician courses at the CTC were transferred to a new establishment called the Institute of Practical Technology (IPT) 
at the present premises of the University of Moratuwa. With the recommendation of the Government appointed Commission of Inquiry on Technical Education report of 1963, IPT earned university status, as the Katubedda Campus of the single University of Ceylon, on $15^{\text {th }}$ February 1972.

The university system in Sri Lanka operates within the framework laid down in the Universities Act 16 of 1978. This reintroduced the system of separate universities functioning under the direction of the University Grants Commission (UGC). Thus the universities, namely, Colombo, Peradeniya, Moratuwa, Jaffna, Kelaniya and Jayawardenapura became separate universities. The UGC, which functions as the apex body in the university system, allocates funds to the universities and institutes, serves as the central admission agency for undergraduate degree courses, monitors and reviews the working of the university system with a view to maintaining standards, and implements national polices in respect of university education. Earlier higher education was under the Ministry of Education. In 2007, a separate Ministry of Higher Education was created to give greater thrust to higher education development. UGC statistics show that there were 15 public universities, 7 postgraduate institutes, and 9 other higher education institutions by 2010. In addition, there are 2 universities for Buddhists studies established under the Ministry of Higher Education.

As per 2010 UGC data, 73,398 undergraduate students were enrolled in the public universities in 2010. In addition, 8,984 students were enrolled in universities for postgraduate degrees and 14,187 students were enrolled in higher educational institutes for certificate, diploma and postgraduate programs. 29,222 students are enrolled in the Open University of Sri Lanka in the year 2010. While seven universities are large and have enrolment in a range of subjects, the remaining are mainly regional universities with small enrolments in science based courses. Another about 150,000 students (with two-third of them women) take exams without attending classes and are 'external students'.

After 13-year of schooling, about 125,284 qualified for admission to the universities in the academic year $2009 / 2010$. Out of this, only 21,547 , which is about $5 \%$ of the average age cohort, were selected for university admissions. Others either found entry into the labour market or appeared for university exams as external students.

\section{Computing Education in Sri Lanka}

More than $50 \%$ of the graduates in the university system are enrolled in arts, science and commerce subjects with low employability. There are few higher educational institutes offering degree and postgraduate degrees in the field of computer science and information technology, where the demanding job opportunities exist in the market. In 2010 only about 2,756 students were enrolled in the field of Computer Science, Information Technology and Information \& Communication Technology (for undergraduate studies) fields by the Eastern University (24), University of Ruhuna (42), University of Kelaniya (168), Sabaragamuwa University (191), University of Jaffna (197), South Eastern University (199), University of Peradeniya (201), Rajarata University (226), Uva Wellassa University (322), University of Moratuwa (449) and the University of Colombo School of Computing (737). In addition the University of Colombo School of Computing registered 2,514 external students for Bachelor of 
Information Technology (BIT), external degree in 2010 and registered 2,560 students in the year 2011. It is the only external degree in IT offered by the university systems. Their total student enrolment for the first year external degree program was 4,181 in 2011.

\section{$4 \quad$ 'Computer Revolution' in Sri Lanka}

As mentioned earlier, the University of Colombo established in the year 1870, could now claim to have been associated with higher education for nearly 140 years, and has become a centre of excellence of international repute that contributes significantly towards national development and human resource development in the field of computer science and information and communication technology through the Department of Mathematics, Statistical Unit, Computer Centre, Institute of Computer Technology and the University of Colombo School of Computing (UCSC). UCSC as a institute celebrated its $25^{\text {th }}$ Anniversary on the $27^{\text {th }}$ October, 2010, and has been in the forefront of the 'Computer Revolution' in Sri Lanka, having introduced the teaching of computer programming and applications as early as in 1967, more than a decade before other educational institutions, thereby producing, over the years, a large number of pioneer computer scientists and IT graduates out of students entering the university from a variety of disciplines. Students who earned knowledge from the University of Colombo are presently employed as researchers, educators, data processing managers, analyst programmers, software engineers and in many other areas in the professional field of information technology, not only in Sri Lanka but also in South and South East Asian as well as the African and Middle Eastern Regions.

\section{$5 \quad$ Teaching FORTRAN without Computers}

Teaching of computer programming and the use of computer applications for research and teaching at the University of Colombo commenced in 1967. The ICL 1901 mini computer at the State Engineering Corporation was used free of charge thanks to the encouragement given by their management towards the introduction of computing at the University of Colombo in Sri Lanka. A few years later in 1971, the Department of Census and Statistics allowed the University of Colombo free computer time on their IBM 360/25. The fact that these installations were close to the University of Colombo and the interest of both organizations in statistical and scientific applications helped the university researchers to make very good use of this invaluable gesture.

According to the 'Development Plan of the Faculty of Science', that the University of Colombo introduced in 1975, the first teaching was restricted to FORTRAN programming for staff and students as an extra-curricular activity. However, within a few years a combined course in Computer Programming and Numerical Methods was introduced as a paper in Applied Mathematics for the general degree. A single course unit in Computer Programming was introduced in the late seventies. The number of courses offered increased in the late 1970s and the course unit system operating at the University of Colombo made it possible to offer a range of third year degree options. After the study: 'The Introduction of Computer Science into Degree Studies in 
Sri Lanka' submitted to the Ministry of Higher Education in 1983 by Professor C. M. Reeves and the Computer Policy Report of NARESA (1984) Computer Programming and Applications became a part of most postgraduate and undergraduate courses in the country. Computer Applications was introduced in some of the courses meant for those who were not scientists. During the initial stage of this activity, practical sessions were not available for the students due to the non-availability of computers at the University of Colombo. However, the students who were keen to take the course unit in FORTRAN and COBOL programming had to imagine the machine's internal functionality and code accordingly to solve problems only on the paper which then had to be transferred to punched cards and sent to a computer elsewhere.

The above programs were initiated by the Mathematics Department of the University of Colombo which was at that time developing the field of Applied Statistics. A Statistical Unit that was established in 1968 at the request of the Department of Mathematics, the Department of Geography and the Faculty of Medicine did not survive long, due mainly to the loss of several key staff members to overseas universities. However, thanks to the support received from the staff of the Department of Applied Statistics of the University of Reading, UK with British funding, the Statistical Unit was revived. The University of Reading was involved in a link arrangement from 1974 and helped the Statistical Unit to progress steadily to become a National Centre for Statistical Research, Teaching and Consultancy. Dr Roger Stern from the University of Reading, UK who had arrived in 1974 on a two year assignment to help develop Statistics at Colombo was very knowledgeable in the use of computers in Applied Statistics and helped establish the Statistical Consultancy and Data Processing Services (SCADPS), the forerunner of many of the later developments.

Dr Roger Stern was instrumental in the establishment of an academic link between the Statistical Unit and the Department of Applied Statistics of the University of Reading, UK with British Government assistance. This link, one of the earliest and most successful of the inter-University links in Sri Lanka, continued until the early nineties and helped establish the M.Sc. Courses in Applied Statistics and also developed Statistical consultancy. Ian Wilson also from Reading who replaced Roger Stern saw those developments through.

\section{Computer Programming Course Units for Non-Science Students}

Under the Higher Education Reforms that took place in 1972 (Jayarthne Report), the Department of Mathematics and the Statistical Unit of the University of Colombo made a remarkable attempt to initiate new course units in Mathematics, Statistics and FORTRAN Programming to the Statistical Services job stream for Faculty of Art degree students following the newly introduced Special Degree in Development Studies. 30 students were selected from 210 reading for the above degree and were given the opportunity to follow a special degree stream which was specially designed and managed by the Department of Mathematics of the University of Colombo. 


\section{First Computer of the University of Colombo}

The requirements of the Statistical Unit of the University of Colombo in the form of computing support for research, consultancy and teaching resulted in a substantial increase on the computing field. Soon thereafter it was felt that the Statistical Unit should have its own computer for teaching and consultancy in addition to using the free computer time available for research at the Department of Census and Statistics as indicated earlier. An HP9825 desktop microcomputer (HP claimed that this is a Desk Calculator) was obtained under the link arrangement with British Government Assistance in 1977. This introduced in-house computing at the University of Colombo and a small Computer Unit was established in 1977. (The Computer Unit was later termed as the Computer Centre in 1981.) Unfortunately, difficulties arising out of the non-availability of local servicing facilities made this excellent machine (at that time) rather unpredictable. In 1978, the HP9825 microcomputer was sent back to the UK for repairs, and it was lost in the process and was never seen again. In 1980, a serious attempt was made to fulfil the need for computing power with a modern computer (proposal for the purchase of a mini computer for the University of Colombo) capable of statistical work and therefore having a configuration allowing the implementation of some of the well-known statistical packages. The result was to have Data General NOVA/4 minicomputer on loan in 1980 and the purchase of a Data General Eclipse S/140 minicomputer in 1981, with time sharing, multi-user interactive capabilities together with adequate disc storage (20 MB), RAM (128 KB) and a magnetic tape drive with eight terminals. The purchase was made possible by the pooling of funds from Netherlands Universities Foundation for International Cooperation (NUFFIC), University Grants Commission (UGC) and the Equipment Vote of the Faculty of Science of the University of Colombo. We wish to record our appreciation of this timely assistance to introduce a multi-user, multitasking computer to the University of Colombo. One major objective in selecting the particular Computer Configuration was the implementation of third party software packages used worldwide such as GLIM, MINITAB and SPSS which have been implemented on this machine, and thus proved to be an invaluable asset, especially in the consultancy service segment of the Statistical Unit.

Up to the early seventies, teaching was confined to one member of staff. In the late seventies, more were available and a post of Computer Programmer was also created. The Statistical Officers and support staff recruited for the Statistical Unit were able to double up as teachers of computing. Some of the academic staff who had obtained their postgraduate degree in statistics overseas also devoted a considerable amount of their efforts towards matters relating to computer applications.

The Computer Centre was formed in 1981 and expanded the curriculum on Computing by introducing a new course in Numerical Analysis to the undergraduate curriculum. At the same time, it also launched courses in Computer Application for non-university students. These courses proved to be very popular amongst both IT professionals and University staff, who up to that time had lacked exposure to formal techniques in Computer Programming. 


\section{Computers Go Public}

One of the main demarcation points of the history of computing in Sri Lanka was the introduction of computers for assisting the Commissioner of Elections to process the results of the National Presidential Election in November, 1982. In late 1981, thanks to the Reading-Colombo Link programme, Colombo made a request to Overseas Development Assistance (ODA), UK for assistance to purchase a few BBC microcomputers, due to be released to the market in 1982. When they did arrive, in October 1982, this remarkable microcomputer was an immediate success and the Computer Centre received much publicity among the public by their computer display which enabled the telecast of the Presidential Elections of 1982 over National Television (Rupavahini). This saw the use of computers to process election results and the release of results as graphics displays for telecasting. For this purpose floppy disk drives for the $\mathrm{BBC}$ microcomputer were used even before they were introduced to the UK market. This process of release of results of every national election has continued without a single break thereafter, with technological improvement at every stage.

The BBC microcomputer was exploited to be used as a tool for teaching statistics, programming and also for research in addition to its value as an aid for promoting computer literacy. In 1983, ODA, UK granted GBP 10,000 in addition to the GBP 3,000 given in 1982 and the UGC grant for microcomputers was used together with this grant to establish a networked laboratory of $13 \mathrm{BBC}$ microcomputers and also purchased several stand-alone BBC microcomputers, Amiga Computers, Acorn computers, WANG-PC computers, A Kaypro-2 and RadioShack TRS80-16 computers with disc drives, second processors and other peripherals and software.

\section{$9 \quad$ First Ever Computer Courses for Public and Government Employees}

With high publicity received by the University of Colombo due to the release of the Computer Assisted Presidential Election results, the Computer Centre was able to inaugurate a Certificate Course in Computer Applications for the general public, to be held during weekends, not interfering with the undergraduate courses. These courses were primarily meant for the employed to gain knowledge of computer applications rather than to those wanting to learn computer programming for employment. Furthermore, preference was given to those in the scientific and educational sectors.

As highlighted by the National Computer Policy for Sri Lanka - Report of the special working committee of the Natural Resources, Energy and Science Authority of Sri Lanka (1983) - the University of Colombo realized an important aspect of the its Computer Centre's extension work through a Computer Literacy programme in Schools. In early 1983, Computer Assisted Education was introduced by the Ministry of Education to three schools as a pilot project and the University of Colombo helped the Ministry in launching its Computer Education Programme through teacher training. Literacy courses were conducted for students of the Institute of Workers' Education of the University of Colombo and proved to be a success. 
While developing its computing facilities and skills of its staff in computing, the University of Colombo also took steps to actively encourage the use of computers in scientific research. A computer exhibition on 'Computers for Scientific Research' was held by the Computer Centre during Annual sessions of the Sri Lanka Association for the Advancement of Science (SLAAS) in December 1982 and several seminars, training sessions etc. have been held since then. The large number of computers and applications exhibited at the Natural Resources, Energy and Science Authority of Sri Lanka (NARESA) sponsored the 'National Exhibition on Science and Technology' held in 1985 clearly indicated the advances made by then.

Due to increased demand the Data General Mini Computer was upgraded to have 15 terminals and later facilities at the Computer Centre were upgraded with an additional Data General MV2000 with 1MB RAM and AOS/VS operating system. There were by then three microcomputer laboratories of BBC microcomputers and accessories at Colombo University. The IBM-PC and WANG-PC computers were in heavy demand. A Kaypro-2 received as a gift, and the RadioShack TRS80-16 were used for student projects as well as consultancy work.

The staff of the Computer Centre succeeded in making the BBC micro a terminal for the Data General minicomputer thus making available a versatile and low cost terminal as well as a device for data transfer between two computer systems.

\section{Computing for National Interest}

Another important contribution by the staff has been the part played in the development of a Statistical Package for the BBC microcomputer and an IBM PC Compatible computer called 'INSTAT', developed with the collaboration of the University of Reading, UK and released to the overseas market (1984). This software has been the basis for many a course in Statistics both in Sri Lanka and overseas.

In technical research in the field of computer technology and the involved in national interest in information technology education since early eighties, the University of Colombo has been actively engaged in the development of local language (Sinhala/Tamil) interfaces for personal computers in applications areas such as word processing, database management systems and spreadsheet applications; a research area nobody has hitherto undertaken in Sri Lanka. This work mainly involves developing software and hardware based solutions for the IBM compatible computers. Development of a very early tri-lingual (Sinhala/Tamil/English) Sinhala Basic Input and Output System - SBIOS and Tamil Basic Input and Output System - TBIOS for IBM PC-DOS with a very popular multilingual (Sinhala/English) word processor

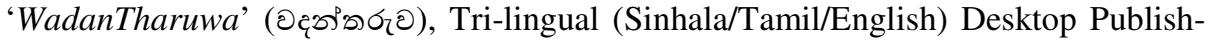

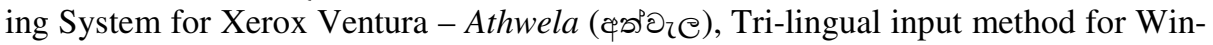
dows 95/98 'Sarasavi' (ఓઢఓల)) packages and a UNICODE version 'WinMASS Sara$s a v i$ ' to the Sri Lankan market. Thus was an invaluable contribution to the nation as a result. The initial product received wide publicity and recognition.

These developments have been part of the pioneering work concerned with the introduction of local language computing and providing a world first ever Indic origin 
tri-lingual National Web Site (www.lk) for the Government Information Department of Sri Lanka, inaugurated by the late Honorable Minister Mr. Dharmasiry Bandaranayake at a public ceremony held in Bandaranayake Memorial International Conference Hall $(\mathrm{BMICH})$ on $15^{\text {th }}$ September, 1996. The Tamil language related research and development activities were continued thereafter.

One of the other major roles played by UCSC and the ICT was to coordinate research and recommend the draft Sinhala Code for ISO/IEC JTC 1/SC 2/WG 2 to include in UNICODE. Based upon the recommendation made by the Computer and Information Technology Council of Sri Lanka (CINTEC) and the subsequent approval of Sri Lanka Standard Institute of Sri Lanka, the ISO/IEC JTC 1/SC 2/WG 2 Meeting \#32 was held in 1997-04-01, in June, 1997 and ISO/IEC JTC 1/SC 2/WG 2 Meeting \#33 held in Crete, Greece where the draft Sinhala Code was discussed intensively. After a few ad-hoc committee meetings with National delegates and other nominated country delegates concluded the repertoire, names, and arrangements for Sinhala script based on Sri Lankan proposal with slight modification with the support of the majority of delegates from Canada, Netherlands, Greece, UK, USA and forwarded to WG 2 for adoption and processing at a pDAM stage. This was ratified at the WG 2 meeting \#34, Redmond, WA; 1998-03-16 held at Seattle, USA and the Sinhala Code Chart was included in Unicode Version 3.0.

Other software developed in terms of national interest includes the graphical display for the media such as the TV Programme Parade, the Cricket Scoreboard, SAAF Games Display and National Quiz programs organized, managed and conducted by University of Colombo in early 1980s.

The computing staff at Colombo has been engaged in dissemination of knowledge to the nation's citizens through public and private media channels for more than two decades. These television and radio programs received the highest ratings and were most popular programs all the time. These programs, namely, the 'Computing for Schools' (5 episodes, 1995), IT programs directed by Daya Liyanage from MTV TV

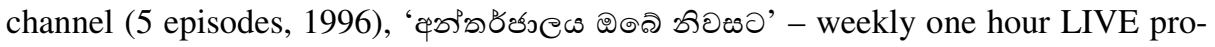
gram for IT related technical discussion on Sri Lanka Rupavahini Corporation (SLRC) (National Television), Sundays 7.00pm - 8.00pm (- more than 150 episodes, 1997-2001), 'Internet and You' a weekly one hour LIVE program for IT and internet related technical discussion on Sri Lanka Broadcasting Corporation (SLBC) Wednes-

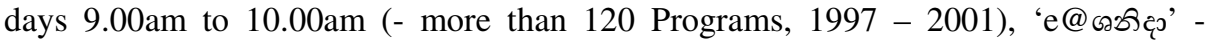
weekly one hour LIVE program for IT related technical discussion on SLRC Sundays 7.00am - 8.00am, (5 Programs, 2003), 'IT-Quiz 2000' nation-wide IT quiz competition telecasted on National Television, 'FORUM for BIT' - a weekly 30 minutes educational TV program for Bachelor Degree in Information Technology (BIT) tele-

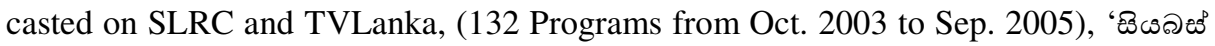

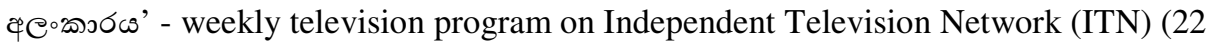

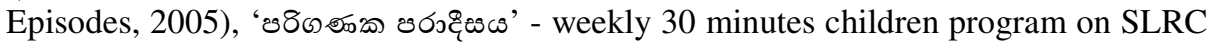
(Thursday 5.00pm - 5.30pm, 2008), 'e-తొฉৃఠరో' - weekly 30 minutes IT program for

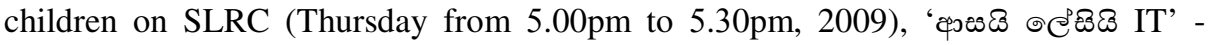
weekly 30 minutes program in Information and Communication Technology for students in schools and universities, and general public on SLRC, ) Saturdays from 


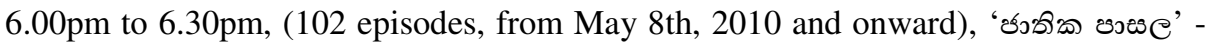
24 programs for 'Information and Communication Technology' for A/L syllabus were recorded and is being telecasting from $1^{\text {st }}$ October, 2011 to $31^{\text {st }}$ of July, 2012 on Rupavahihi and many other programs on National and other Television channels for IT related discussions.

\section{Early Regional Collaboration}

The University of Colombo was involved with the organisation of the First Asian Regional College on Microprocessors in June 1984 supported by the International Centre for Theoretical Physics, Triest and co-sponsored by the UGC and the Council for Information Technology (CINTEC). This benefited 40 foreign and 32 Sri Lankan participants. A sum of US\$ 120,000 was raised for the Collage. Of this US\$10,000 was funds earmarked for the University of Colombo by UNESCO. This resulted in a valuable set of books being made available for the Library. Another international course was supported by the University of Reading and cosponsored by the Computer Centre and the Statistical Unit in December, 1984, on 'Statistics in Agriculture', with a heavy bias towards computer use in agriculture. 14 Foreign and 10 Local participants took part and they were supported by several international and national organizations including the Agrarian Research and Training Centre, Sri Lanka to mark the tenth Anniversary of the Colombo-Reading Link. This was repeated in 1985 for 30 local participants. It was during this course that the Statistical Unit of the Mathematics Department was elevated to the status of a Department - that of Statistics and Computer Science (DSCS).

In 1984, the Computer Centre helped the British Council and the Ministry of Education to conduct a two week course on 'Computer Education' for school teachers and curriculum developers. All these activities have provided valuable experience to the staff and have also contributed significantly towards promoting the development of computer applications in the country.

\section{Staff Exchange Programs and Postgraduate Training}

The British Assistance for Statistics provided for staff training in Computing too through a link with the University of Reading, UK. The UGC initiative following the Reeves Report 'On the Introduction of Computer Science in to Degree Studies in Sri Lanka - A report to the Ministry of Higher Education' (1983) also provided training in Computing at the University of Wales, UK. Subsequent support from the UNDP helped continue this trend. Many staff members returned with a Diploma, M.Sc., M.Phil., and PhD. in Computer Science during 80s and 90s as a result of these initiatives. Many received training in Japan too. Although there was some staff loss to the private sector or overseas, new blood was pumped into the Centre and incentives in the form of job satisfaction, additional remuneration received from extension courses and consultancy work, and an ever improving range of available hardware and software and good work environment, together with challenging projects made many stay, in spite of much better job prospects elsewhere. 
As a result of the staff exchange programs, the University of Colombo actively engaged in developing study guide books for students and lecturers of the universities to introduce 'Software Design and Implementation: A PASCAL Based Course' with collaborative assistance received from the University of Keele, UK and The British Council, for the purpose of course material preparation. These materials were used by undergraduates in all the universities of Sri Lanka.

\section{Collaborative Research Activities}

A collaborative research project on crop and climate data between the University of Colombo and the University Reading resulted in a database being developed at Colombo University and many local and overseas groups and Research Institutes were able to obtain data for their research. This Crop and Climate Database project computerized the range of daily climate data, including temperature, rain, wind etc. collected from 100 metrological stations established around the island for the past 100 years. This, together with the consultancy work done in the areas of Agriculture, Health and Education made the Computer Centre a very useful resource in Sri Lanka. It developed expertise in the packages INFORMIX, SAS and SPSS and became the only expert group for such packages in the county at that time.

Collaborative work with Research Institutes such as the Rubber Research Institute (RRI), Tea Research Institute (TRI), Coconut Research Institute (CRI) and Meteorology Department grew during early 1980s with advice given on computing including evaluation of needs and assistance in purchasing of computer equipment and also training. The Centre was also able to give five microcomputers on loan to the Research Institute, complete with the Statistical Package INSTAT.

\section{Establishment of a Fully Fledged Academic Department for Computing}

In 1984, the Department of Mathematics made a proposal for the Establishment of a Computer Centre, a Department of Computer Science and Statistics and the commencement of a Postgraduate Diploma Courses in Computer Science submitted to the UGC. In January 1985, the existing Department of Mathematics split into two departments; one remained as the Mathematics Department, and the Department of Statistics and Computer Science (DSCS) was formed by merging the Statistical Unit and Computer Centre. It was only in 1986 that the formal separation took place as the separation of activities was not a simple exercise. The new department thus inherited skills in both disciplines and consequently occupies a unique position in the University system in Sri Lanka as a centre of excellence in both these fields. The new department's major objectives at the time of formation were to run specialized degree programs in both Statistics and Computer Science. To this end, further staff training was undertaken and M.Sc. qualified staff enrolled for Ph.D. research programs at British Universities with the help of more British Government aid. Immediately after the establishment of DSCS, a Postgraduate Diploma in Computer Applications was launched in 1986. 
In 1987, Computing took a quantum leap forward with the establishment of a link between the DSCS and the Department of Computing Mathematics, University of Wales Collage of Cardiff, UK. This was made possible through a UNDP sponsored project which was set up to improve the Computing teaching infrastructure in the Department. Both B.Sc. and M.Sc. degree programs in Computer Science that resulted from this have proved to be very popular, with demand far exceeding the number of places available. The M.Sc. programs in Applied Statistics and Computer Science at the DSCS provided very cost-effective alternatives for the training of academic staff from local universities, and a number of such staff have availed themselves of this opportunity. The local IT industry has also benefited from this program with the availability of graduates with the right mix of theoretical and practical skills.

As of 1995, the DSCS further improved its Statistical Education initiative by introducing a special degree course in Statistics at undergraduate level and by restructuring its M.Sc. course in Applied Statistics to a more streamlined form. The special degree course in particular benefits from students undertaking placements in industry in the final year, thus enabling them to do projects which are relevant to the country at large.

The Department of Computer Science (DCS) of the University of Colombo was established in 2001 by splitting the Department of Statistics and Computer Science (DSCS), which functioned since 1985 as part of the Faculty of Science of the University of Colombo. While the DCS was responsible for undergraduate and postgraduate training in Computer Science, the Department of Statistics (DS) was responsible for statistics education in both undergraduate and postgraduate education.

Although the University of Colombo produced graduates with computer science as a subject for some years, its first batch of students specializing in Computer Science and obtaining the B.Sc. special degree graduated in 1992, the first such group in Sri Lanka.

\section{Establishment of Institute of Computer Technology (ICT)}

In early 1984, the University of Colombo Computer Centre, while consolidating its position as a leading computer installation and consultancy service, worked on plans for the establishment of an Institute of Computer Technology (ICT) with the assistance of the Japanese Government. Final approval was granted by the mission that visited Sri Lanka in March 1987 making available funding - amounting to 490 million Japanese Yen - from the Japanese fiscal year 1987/88. The agreement signed by the two governments required the Sri Lankan Government to provide building space, staff and their salaries and recurrent expenditure for the ICT.

An initiative of CINTEC, the University of Colombo and the UGC resulted in the establishment of the ICT at the University of Colombo in 1987 as an Institute established under the Universities Act. The ICT was provided with the largest mainframe computer system in the country then with other peripherals and staff training under Project Type Technical Co-operation of the Japan International Cooperation Agency (JICA), Government of Japan. The ICT was to conduct Postgraduate 
training programs to produce Analyst Programmers for the country. This was a result of the Japanese Mission's visits to the Computer Centre of the University of Colombo in April 1984 and in February 1986 in relation to the proposed Institute and very hard negotiations to win from among several proposals from other countries. Finally the University of Colombo was able to convince the Japanese Mission as well as the Government of Japan, of the need for such an institution. This was a milestone of success of computer education in Sri Lanka.

\section{Third Country Training Programs}

The Japanese assistance provided to the Institute of Computer Technology resulted in building sufficient capacity both in human resources and in facilities. The donor having seen the satisfactory completion of this phase moved on to the next where the ICT was expected to use these resources to provide training for those from other (third) countries through the Third Country Training Program (TCTP). Accordingly, from 1993 to 1998 a TCTP in Structured Systems Analysis and Design was held annually from fifteen Asian countries. On successful completion of this program, a second TCTP in Information Systems Engineering was conducted from 1998 to 2002 for twenty participants each from eighteen Asian, Far East and African countries. In 1998 the ICT received the JICA President's Award for the Best Regional Training Centre among its 60 JICA assisted countries. This excellent concept of south-south cooperation was later introduced to Sida, the Swedish international development agency who sponsored a TCTP in the Design, Installation, Management and Maintenance of Network Systems for twenty participants from Asia, Africa and even Latin American Countries for a few years.

\section{First Decade of the $21^{\text {st }}$ Century}

The developments in Computing indicated above resulted in the University of Colombo becoming a Centre of Excellence by the dawn of the new millennium. Several landmark events took place thereafter enabling the consolidation of the status it had built up in the last four decades of the $20^{\text {th }}$ Century.

The ever increasing demand for IT graduates both globally and locally combined with the inadequacy of the state sponsored free education system prompted the staff of the ICT together with DCS to launch a very innovative external degree program for the Bachelor of Information Technology Degree (BIT). This was an instant success with over 5,000 students registering for year one in 2000. The ICT and DCS developed the curriculum and were to hold the examinations while the University of Colombo was to award the degree. The private sector was to provide the training as the students were registered as external students. This was supplemented by web based course details, on-line course materials, quizzes, model papers and answers and also by a weekly IT program. This was an excellent example of Public-Private Partnership with over 50 private educational institutions preparing students for the BIT. Under the able leadership of Professor V. K. Samaranayake, the DCS and the ICT were able to 
negotiate substantial donor funding for human resource development and infrastructure from the Swedish government under the Sida/IT program in 2000. In the meantime the DCS and the ICT also received substantial equipment and postgraduate funding from ADB and JICA under Government of Sri Lanka auspices.

In the September of 2002, the Institute of Computer Technology and the Department of Computer Science of the Faculty of Science merged to form the University Of Colombo School of Computing, or UCSC, as a centre of Higher Learning affiliated to the University of Colombo with a fair amount of financial and administrative autonomy. This merger helped to bring together over 20 academic staff with $15 \mathrm{PhDs}$ and a large number of postgraduate qualified IT specialists and also all the resources of the two institutions under a single entity. The UCSC has three academic departments and five centres. It is now enjoying the status of being the best IT centre for higher education in the country. UCSC commenced its undergraduate teaching in earnest with a three year Bachelor of Computer Science degree, a four year Bachelor of Science in Computer Science degree with intake of 240 students annually, in addition to continuing its ongoing special degree in Computer Science with the Faculty of Science. Under the MOU signed with the Faculty of Science a very close collaboration was envisaged with UCSC staff involved in teaching faculty students for Joint Honours degree programs with a substantial computing component. The BIT degree continued as usual with an annual intake of around 2500 (http://www.bit.lk) and three new Masters programs namely in, Computer Science, Information Technology and Advanced Computing commenced in October 2002 catering to around 200 part time students. In 2002, UCSC was successful in obtaining a large JICA grant - amounting to 390 million Japanese Yen - to establish ad Advanced Digital Media Technology Centre (ADMTC) equipped with multimedia laboratories, a professional Digital Recording Studio and funding for collaborative research project with leading Japanese universities to build the capacity in the field of web based teaching. The established tradition of third country training programs continued with JICA support and the last multimedia development course under the current funding phase concluded this entry.

The Sida/IT project which commenced in 2000 was extended to two phases and concluded in August 2010. The Sida/IT project was unique in the way it opened $\mathrm{PhD}$ opportunities to computing academic staff from all state universities in Sri Lanka. Staff of universities from Jaffna, Peradeniya, Ruhuna and UCSC obtained PhD and M.Phil qualifications from Uppsala, Stockholm, KTH, Mid Sweden, Gottenburg and Halmstad universities in Sweden enriching the local university human resources. This also spurred staff exchanges between local counterpart universities and those in Sweden. Under the infrastructure development, the LEARN network connecting all universities in Sri Lanka was strengthened with campus-wide fibre networks and wide band access to internet. In all this, UCSC played a key role in coordinating all activities and providing the necessary technical support.

Asia eBIT was a project that was started in the first quarter of 2005 to improve the quality of the BIT program through e-learning services and it was funded by the European Union. It was a three year project which had two foreign partners, the Department of Computer and Systems Science (DSV), the Royal Institute of Technology (KTH - Kungliga Tekniska högskolan), Stockholm University in Sweden and Delft 
Technology University in Netherland and which also provided for staff exchange and $\mathrm{PhD}$ opportunities for local staff. Highly motivated staff were also able to secure many foreign grants for specialized research in the areas of grid computing (SPIDER), information security (SPIDER, ISIF) and language processing (IDRC).

In 2002, UCSC commenced another undergraduate degree program carefully taking into consideration the needs of the industry; this was called the Bachelor of Science in ICT, both a three year and a four year degree - in effect an Information Systems degree. The UCSC continued to evolve its postgraduate studies and research capabilities, redesigning the masters programs into Masters in Computer Science, Masters in IT and Master of Science in Information Systems Security, and registering a number of M.Phil and $\mathrm{PhD}$ students while utilizing the generated funds to enhance staff research capabilities. UCSC commenced its own journal publication in 2008, called ICTER, the International Journal on ICT for Emerging Regions, which is widely circulated around the world, and is moderated by an international advisory panel. At the same time, UCSC in its pioneering spirit formed a company called Theekshana to work towards national development goals in e-governance and other areas, by utilizing the in house expertise of is academic staff in strengthening industry-university collaboration.

UCSC was proved and announced at this stage that responsibility was taken to conduct the fully automated on-line training programs as part of the pre-orientation program, which was a tailor made program for 22,500 New Entrants to Universities in order to improve English Language and Information Technology skills. This has been conducted for a period of three months from July to September 2011 before they enter the University in October. The courses and the on-line tests, (both pre and post) was developed by UCSC and conducted through the NODES - The National Online Distance Education Service of the Ministry of Higher Education. NODES have access to a fibre network of 26 state-of-the-art NODES Access Centres island-wide to complete the above tasks. These centres includes 660 high end multimedia PCs for individual use, video conferencing facilities to connect 20 centres simultaneously, scanning and printing services and are staffed with knowledgeable operators for onsite assistance to students. These centres are networked with high speed fibre communication line bandwidth to have minimum of $2 \mathrm{Mbps}$ dedicated to centres, $45 \mathrm{Mbps}$ dedicated access to Network Operating Centre and $10 \mathrm{Mbps}$ dedicated access to Internet. As noted elsewhere, apart from the academic departments, UCSC also has a number of centres, ranging from professional development, external degrees, e-learning and network operations (serving the whole of the University of Colombo) to forensics.

\section{Conclusion}

Sri Lanka has throughout its recorded history given priority to human development and in particular towards education. This has resulted in a high quality of life even though pure economic indicators make the country one that is still developing. In the field of computing, which was recognized as important even in the late sixties, a strategy of sharing whatever knowledge one had without awaiting expensive resources has 
shown results. Another aspect was the policy of computers for all ages, professions and for the society at large. The development of Computer Education has been well planned taking into account not only the currently available technology but also future trends as envisaged by the policy makers. This included the provision of resources, both human and material, and the strategic and optimum utilization of limited donor assistance. These initial steps have quite rightly led to international recognition and regional collaboration.

Today, the UCSC continue to grow from strength to strength, providing beyond doubt, the benefit of the initial planning and positive approach of the successive development phases of its predecessor institutions and their members. Its stature as a centre of international repute and success is also a strength to the many donors who have assisted in the early development efforts who can now see positive results from their investment in development.

With the demise of its founding director and mentor, Professor V. K. Samaranayake in 2007, an era came to an end confirming one of the nature's certainties. However, in the true spirit of this giant man in the national Information Technology landscape, and the institutions and the human resources base he was so dedicated in building up, the UCSC and of its predecessor institutions and their members shall continue its ground breaking activities beyond its 45 years of hard work and looks forward with pride and eagerness to continue its mission for the nation and its citizens. 